\title{
A Quasi-Lumped Element Series Array Resonator Antenna
}

\author{
Seyi Stephen OLOKEDE \\ School of Electrical \& Electronic Engineering, Universiti Sains Malaysia, 14300 Nibong Tebal, Penang, Malaysia \\ solokede@gmail.com
}

\begin{abstract}
This paper presents a 6-element series array quasi-lumped element resonator antenna. The proposed antenna employs an interdigital capacitor in parallel with a straight strip conductor whose center finger is shorted across the capacitor. An array configuration is imperative as the gain of a single quasi-lumped element arrangement was only moderate and specifically put at about $9.4 \mathrm{dBi}$ which may not be adequate for long distance communications.
\end{abstract}

Relevant Equations for radiation pattern of the quasilumped element resonator (QLER) were derived and presented. The proposed antenna array exhibits a gain enhancement up to about $29.47 \%$ with a noticed size reduction of $80 \times 30 \mathrm{sq} . \mathrm{mm}$. Compared to standard long wire antenna and other approaches of capacitive loaded long wire antennas, it was proved that the proposed antenna has a relatively better performance yet with significant size reduction. Consequently, it is an ideal candidate for MMIC designs and wireless communication applications.

\section{Keywords}

Coupled structure, loop, microstrip patch, triangular antenna, quarter wavelength

\section{Introduction}

Quasi-lumped concept is widely used in microwave circuit design in recent times. Generally, they are passive components whose size across any dimension is much smaller than the operating wavelength to ensure that there is no appreciable phase shift between the input and output terminals. They have the advantages of lower cost, smaller size and wider bandwidth characteristics. Besides, impedance transformation close to 20:1 is feasible using QLERs [1]. Hence, these make them attractive candidates for antenna design as a result of their size reduction capability. Miniaturization and performance improvement of antennas are still a great challenge today. Fundamentally, compact single-element antennas suffer severe limitations in term of gain most especially as a result of size reduction. When the size of the antenna is reduced, the single-element provides low value of directivity as a result of reduced radiative resistance. This leads to the problem of decreased radiative efficiency as the ratio of the antenna conductor to the radiated power decreases as frequency increases [2], [3].

Consequently, many planar antenna arrays in a view to solving the directivity limitations of single-element for different antenna types have been reported, and these works even though are array configurations; either suffer relatively large antenna real estate, or low gain or both. Yet a compact and lightweight antenna will be adequate in order to support high mobility requirement for most wireless applications. Hence, the proposed structure is one of the few useful resonators to achieve compactness, yet with reasonable directive characteristics. This is because at RF, lumped-element leads to significant size reduction without necessarily affecting its performance [4], [5]. Thus, the compactness leads to increase in the number of chips per wafer, and as such, reduces chip cost drastically.

This paper therefore, presents a QLER antenna array for wireless applications. The objective of this article is three folds. The first is to demonstrate the proposed antenna's size reduction capability. The second is to derive the relevant equations for the antenna radiation pattern, and finally, to compare the proposed antenna performance first, with similar works reported in the literature, and secondly, with the standard long wire antenna, and more particularly, the capacitive loaded wire antenna and planar H-shaped elements transmission-line in order to demonstrate its specific advantages.

\section{Theoretical Development}

Limitations of low radiative resistance, high Q-factor, narrow bandwidth, feeding difficulties are among the numerous challenges confronting the feasibility of designing small antennas. The trade-off between antenna size and performance is in general difficult to predict for practical situations, particularly where matching units are involved and evaluations tends to be experimental. Because of this, designers in many sector of the market are now demanding more precision in small antenna design, so that any performance penalties incurred can be minimized. The coaxial feed is therefore located at a particular offset coordinate 
position away from the radiator in order to be excited magnetically. This is because it has been pretty difficult to excite the radiator due to its size relatives to the feed size. More importantly, optimization using microwave studio indicates that a dominant mode occurred at $\mathrm{TM}_{10}$.

Figure 1 depicts the magnetic coupling excitation of a single-element QLER antenna with the coaxial feed arrangement. The effect of the first half cycle of the sinusoidal excitation source is captured as seen in the figure, whereas, the second half cycle excites the lower part of the single QLER alternately. The magnitude of voltage and current distribution on a short circuited line of a wavelength long are as shown in Fig. 2 [6]. While it is expedient to employ inter-element spacing of $\lambda$, the wavelength long spacing will not only lead to a large estate occupation, multiple maximal of equal magnitude radiation pattern can also be formed.

Instead, a half wavelength inter-element spacing is used based on voltage allocation on a short ended transmission line. When a transmission line is not matched to its load, some of the energy is absorbed by the load and some is reflected back down the microstrip line towards the source, the interference of incident wave and reflected

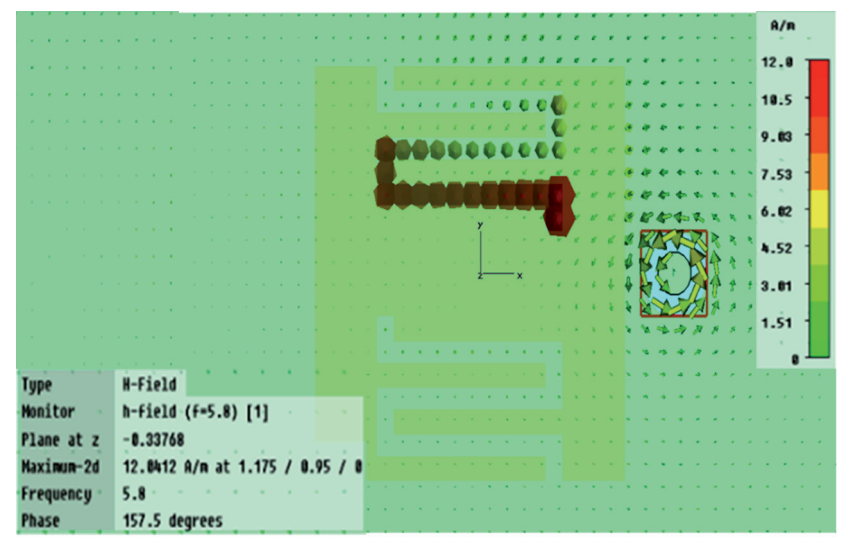

Fig. 1. The excitation mechanism of the coaxial-excited magnetically coupled single quasi-lumped element resonator antenna.

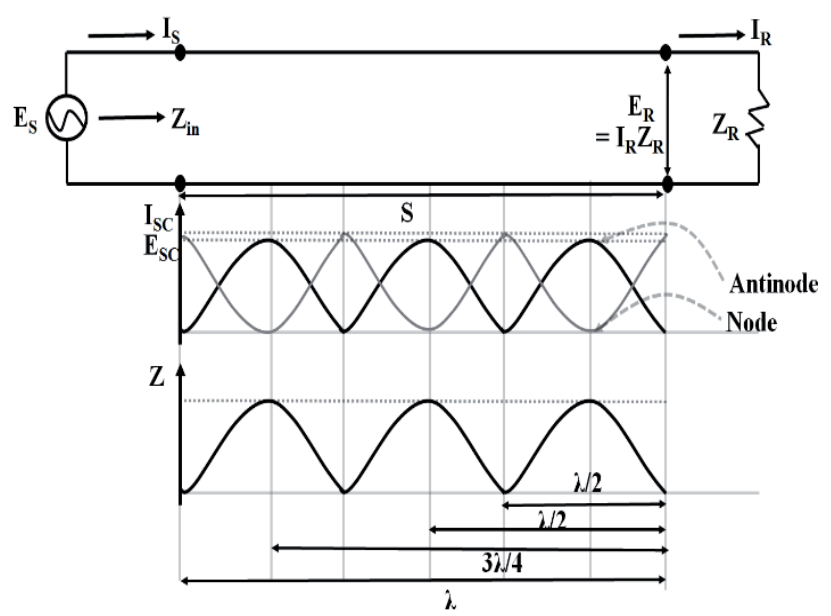

Fig. 2. Input impedance, current and voltage variation along short circuited microstrip line. waves creates the standing waves on the transmission lines. Nodes (where voltage or current is minimum) and antinodes (where voltage or current is maximum) are periodically created along the transmission line from the load completion toward the generator when the load end of the line is shorted.

Seeing the antinodes will repeat itself at every half wavelength along the transmission line, the array elements were positioned at every half wavelength along the microstrip feed line in order to get the maximum radiation at every antinode from the source down to the load completion.

\subsection{The Radiation Characteristic Equations of the Proposed Antenna}

At any constant $z$ position, the electric field distribution far away from the radiating element (the single QLER) edges is periodic in the $x$ direction and assumed uniformly in the $y$ direction.

Figure 3 shows the QLER in $x y$-plane with the origin at the center [7]. $\mathrm{p}(x, y, z)$ is an arbitrary point in space and $\mathrm{p}^{\prime}\left(x^{\prime}, y^{\prime}\right)$ is an arbitrary point on the radiating element. The center of the radiating element is located at the origin. For the periodic interdigital capacitance with uniform potential across the gap, the current density per finger is stated as [8]

$$
J\left(x^{\prime}, y^{\prime}\right)=\frac{2}{\pi w \sqrt{1-\left(\frac{2 x}{w}\right)^{2}}}, \quad-\frac{l}{2} \leq x \leq \frac{l}{2}
$$

where $x$ is measured transversely from the center of the strip. The current at the edges of each finger shows singular behavior, each of which depends on two variables $\left(x^{\prime}, y^{\prime}\right)$ representing the observation point coordinate with respective surface wave components $J_{\mathrm{x}}\left(x^{\prime}, y^{\prime}\right)$ and $J_{\mathrm{y}}\left(x^{\prime}, y^{\prime}\right)$ which are approximated by factors stated as

$$
\begin{aligned}
& J_{x}\left(x^{\prime}, y^{\prime}\right)=\frac{1}{\pi w_{c} \sqrt{1-\left(\frac{2 x^{\prime}}{w_{c}}\right)^{2}}}, \\
& J_{y}\left(x^{\prime}, y^{\prime}\right)=\frac{1}{\pi w_{c} \sqrt{1-\left(\frac{2 y^{\prime}}{w_{c}}\right)^{2}}} .
\end{aligned}
$$

It is evident that the surface wave distribution on the entire interdigital capacitor is continuous but with singularities at the edges of each finger throughout the entire structure. Thus, the sinusoidal approximation of current on interdigital structure is contingent on the gaps between the fingers of the structure, and as such, must be taken into consideration by the current approximation. To this end, the assumption of asymptotic behavior of the currents at the metallic edges of each finger of the interdigital capacitor structure will be incorrect. Rather, this behavior is defined correctly by Meixner condition [9], [10]. 


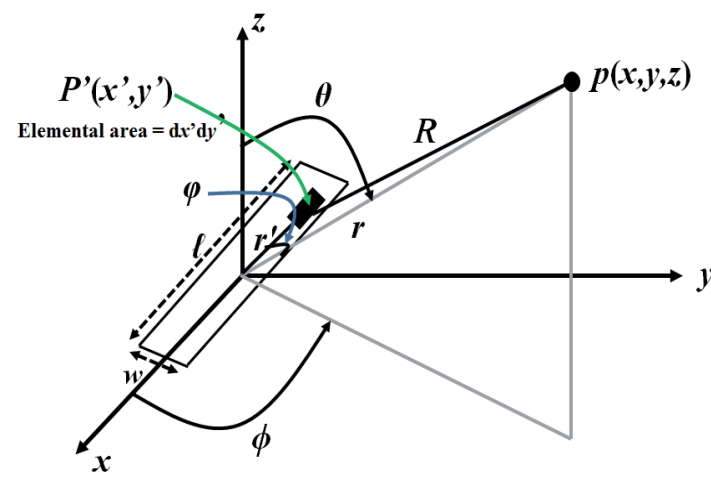

Fig. 3. Spatial coordinates of the antenna radiation analysis.

To that extent, the spectral current component $J_{\mathrm{x}}$ and $J_{\mathrm{y}}$ are expanded in terms of linear combinations of these following basis functions, recognizing the singularities between the fingers [11], the values of which can be determined by equations stated in (3) and (4).

$$
\begin{aligned}
J_{x}\left(x^{\prime}, y^{\prime}\right)= & \frac{\cos \left(\frac{2 \pi}{w_{c}} x^{\prime}\right)}{\pi w_{c} \sqrt{1-\left(\frac{2 x^{\prime}}{w_{c}}\right)^{2}}} n=0,2,4,6, \ldots \ldots \ldots, 2 n \\
& \frac{\sin \left(\frac{2 \pi}{w_{c}} x^{\prime}\right)}{\pi w_{c} \sqrt{1-\left(\frac{2 x^{\prime}}{w_{c}}\right)^{2}}} n=1,3,5,7, \ldots \ldots \ldots,(2 n+1) \\
J_{y}\left(x^{\prime}, y^{\prime}\right)= & \frac{\cos \left(\frac{2 \pi}{w_{c}} y^{\prime}\right)^{\prime}}{\pi w_{c} \sqrt{1-\left(\frac{2 y^{\prime}}{w_{c}}\right)^{2}}} n=0,2,4,6, \ldots \ldots \ldots, 2 n \\
& \frac{\sin \left(\frac{2 \pi}{w_{c}} y^{\prime}\right)}{\sqrt{w_{c} \sqrt{1-\left(\frac{2 y^{\prime}}{w_{c}}\right)^{2}}}} n=1,3,5,7, \ldots \ldots \ldots, 2(n+1)
\end{aligned}
$$

These sets of basis functions satisfy edge conditions at the radiating elements and their Fourier Sine and Cosine transformations are simple zero-order Bessel functions of the first kind. It is noteworthy also that the singularities of the current distribution at the edges are incorporated in the equations describing the voltage/current travelling in dissipationless transmission line etched a dielectric substrate. Therefore, the total surface current density of the entire interdigital structure at the point of observation $\left(x^{\prime}, y^{\prime}\right)$ is stated as

$$
J\left(x^{\prime}, y^{\prime}\right)=\sum_{i=0}^{N}\left[J_{x i}\left(x^{\prime}, y^{\prime}\right)+J_{y i}\left(x^{\prime}, y^{\prime}\right)\right]
$$

where $i$ is the $i$-th finger, and $N$ is the total number of fingers. Hence, the radial electric field equations for azimuth and elevation are given in (6) through to (9) below [12], [13].

$$
\begin{aligned}
& E_{\theta}=-j \eta\left[\frac{\sin \left(\frac{k_{0} w}{2} \sin \theta \sin \phi\right)\left(\cos \left(\frac{k_{0} l}{2} \sin \theta \cos \phi\right)-\cos \left(\frac{k_{0} l}{2}\right)\right)}{k_{0} w \tan \theta \tan \phi\left(1-\sin ^{2} \theta \cos ^{2} \phi\right)}\right] I_{0} \times J\left(x^{\prime}, y^{\prime}\right) \\
& E_{\phi}=j \eta\left[\frac{\sin \left(\frac{k_{0} w}{2} \sin \theta \sin \phi\right)\left(\cos \left(\frac{k_{0} l}{2} \sin \theta \cos \phi\right)-\cos \left(\frac{k_{0} l}{2}\right)\right)}{k_{0} w \sin \theta\left(1-\sin ^{2} \theta \cos ^{2} \phi\right)}\right] I_{0} \times J\left(x^{\prime}, y^{\prime}\right)
\end{aligned}
$$

$$
H_{\theta}=-j\left[\frac{\sin \left(\frac{k_{0} w}{2} \sin \theta \sin \phi\right)\left(\cos \left(\frac{k_{0} l}{2} \sin \theta \cos \phi\right)-\cos \left(\frac{k_{0} l}{2}\right)\right)}{k_{0} w \sin \theta\left(1-\sin ^{2} \theta \cos ^{2} \phi\right)}\right] I_{0} \times J\left(x^{\prime}, y^{\prime}\right)
$$$$
H_{\phi}=-j\left[\frac{\sin \left(\frac{k_{0} w}{2} \sin \theta \sin \phi\right)\left(\cos \left(\frac{k_{0} l}{2} \sin \theta \cos \phi\right)-\cos \left(\frac{k_{0} l}{2}\right)\right)}{k_{0} w \tan \theta \tan \phi\left(1-\sin ^{2} \theta \cos ^{2} \phi\right)}\right] I_{0} \times J\left(x^{\prime}, y^{\prime}\right)
$$

Consequently, the total electric and magnetic fields are given in (10) and (11).

$$
\begin{aligned}
& E=\left[\left(E_{\theta}\right)^{2}+\left(E_{\phi}\right)^{2}\right]^{0.5}, \\
& H=\left[\left(H_{\theta}\right)^{2}+\left(H_{\phi}\right)^{2}\right]^{0.5}
\end{aligned}
$$

where $\eta=(\omega \mu) / k_{0}$ and $k_{0}=(2 \pi) / \lambda$ is the wave number in free space. The theoretical equations of the far-field radiation patterns of the single QLER are presented in (6) to (11). Hence, the equations of the spatial radiation patterns of the proposed array of the six identical elements are evaluated at a location $(\theta, \varphi)$ in the far-field, and can be approximated by multiplying the radiation intensity of the single element stated in (10) and (11) by the array factor stated in (12),

$$
A F=\frac{1}{m} \frac{\sin \left[m\left(k_{0} d_{y} \sin \theta \cos \phi\right) / 2\right]}{\sin \left[\left(k_{0} d_{y} \sin \theta \cos \phi\right) / 2\right]}
$$

where $m$ is the number of array elements, and $d_{y}$ is the inter-element spacing. The resulting equations were then plotted, and further validated by comparing it with the simulated and measured results in order to determine the level of agreement. The findings are as shown in Fig. 9.

\section{Antenna Design}

\subsection{Single Quasi Lumped Element Resonator Antenna}

The single QLER antenna shown in Fig. 4 was printed on a Roger Duroid RO4003C microwave substrate of $0.813 \mathrm{~mm}$ thickness and relative permittivity of 3.38 . 


\begin{tabular}{llllllll}
\hline $\begin{array}{l}\text { Dimensions } \\
\text { of the } \\
\text { Proposed } \\
\text { Antenna }\end{array}$ & $\begin{array}{l}\text { Straight } \\
\text { Line } \\
\text { Inductor } \\
\text { Width } \\
(W)\end{array}$ & $\begin{array}{c}\text { Inductor } \\
\text { Length } \\
\left.a_{L}\right)\end{array}$ & $\begin{array}{c}\text { Capacitor } \\
\text { Finger } \\
\text { Width } \\
\left(w_{c}\right)\end{array}$ & $\begin{array}{l}\text { Number of } \\
\text { Interdigital } \\
\text { Finger } \\
(N)\end{array}$ & $\begin{array}{l}\text { Distance } \\
\text { Between } \\
\text { Fingers } \\
\left(g_{e}\right)\end{array}$ & $\begin{array}{l}\text { Overlapping } \\
\text { Width of } \\
\text { Interdigital } \\
\text { Finger } \\
\left(C_{L}\right)\end{array}$ & $\begin{array}{l}\text { Total } \\
\text { Antenna } \\
\text { Size }\end{array}$ \\
\hline $\begin{array}{l}\text { Parameters } \\
(\mathrm{mm})\end{array}$ & $\mathbf{1 . 2}$ & 3.35 & 0.35 & 8 & 0.3 & 3.05 & $5.8 \times 5.6$ \\
\hline
\end{tabular}

Tab. 1. Design parameters of the proposed single QLER radiating element.

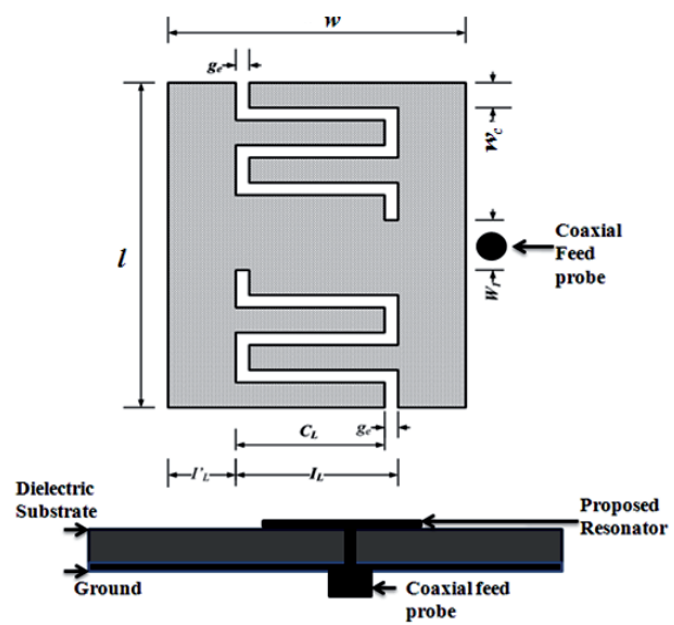

Fig. 4. Geometry of a single quasi-lumped element resonator antenna.

The antenna was fed by microstrip line of $50 \Omega$ of approximate width of $1.898 \mathrm{~mm}$ and excited by a coaxial feed probe. The design was based on the dimensions obtained from (1) to (3) stated in [4], and the parameters are as follows: $l=5.8 \mathrm{~mm}, w=5.6 \mathrm{~mm}, C_{L}=3.05, g_{e}=0.3 \mathrm{~mm}$, $W_{1}=1.2 \mathrm{~mm}, w_{c}=0.35$ and $I_{L}=3.35 \mathrm{~mm}$ as stated in Tab. 1.

These values are then substituted into other design equations stated in [3], [4] to determine the values of interdigital capacitance $C$, strip inductance $L$, and the pad capacitances $C_{\mathrm{p} 1}$ and $C_{\mathrm{p} 2}$; and finally obtain the desired resonance frequency $f_{0}$ of the design using (4) of [4]. QLER offers a high degree of design freedom and flexibility. To this end, two QLER antenna models operating at the same frequency can be designed and yet, with different dimensional parameters depending on the desired design considerations. This possibility is obtainable based on parametric optimization implemented by either adjusting the center inductance $L$ or the pad capacitances $C_{\mathrm{p}}$, or both as demonstrated in Tab. 2 of [4].

\subsection{Feed Configuration of the Array}

The proposed antenna design was excited by a coaxial feed located at the second element whereas the entire arrangement is fed by a microstrip feeder. The microstrip feed line was used as feed in order to ensure that power is distributed evenly to the individual elements in equal magnitude and phase across every element of the array to achieve linear polarization whereas, the coaxial feed probe excitation was used due to its identified capacity for improved impedance match, to wit, the bandwidth, reflection coefficient and performance improvement capabilities. Fig. 5 shows the voltage allocations on a microstrip line with termination at the load end, such that the array interelement spacing is based on the calculation of the guided wavelength $\lambda_{\mathrm{g}}$.

In a series feed array configurations, the input impedance of one of the radiating elements acts as a load to the former array component. Thus, the first element is usually positioned at a quarter wavelength from the stub end in a series feed open ended stub, which in turn acts as the load. Seeing that the antinodes will repeat itself at every half wavelength along the transmission line from the load completion toward the source, the other four elements of the array will naturally take their positions at every half wavelength in order to get maximum radiation of the array.

The sixth element is then positioned at a location $\mathrm{X}$ such that it is not less than a $\lambda / 4$ to forestall the possibility of an incoming node. The same impedance and voltage condition is periodic every half-wavelength down further the line from the load as demonstrated in Fig. 2. In essence, it is expected that the radiating elements will constructively add up the radiated power produced by individual radiating element in free space, and as such enhance the directive characteristics of these radiators in terms of gain, beamwidth, sidelobe level etc. The far-field radiation pattern of the QLER antenna was obtained by multiplying element pattern by the series array factor $A F$.

\subsection{Design of the Antenna Array}

The antenna was designed as shown in Fig. 6. Though a similar design with a relative size reduction advantage is a possibility, but with a suspended substrate, will be too bulky to be readily installed on typical dimensions of a slim mobile communication handheld gadget. Consequently, all other antenna elements were positioned at $d_{y}=\lambda_{\mathrm{g}} / 2$. The guided wavelength was calculated to be $28 \mathrm{~mm}$; the half- wavelength was equal to $14 \mathrm{~mm}$ while the quarter-wavelength was $7 \mathrm{~mm}$. The radiating elements are proportionately positioned as earlier explained in Sec. 3.2. The sixth radiating element was experimentally set at $\mathrm{X}=10 \mathrm{~mm}$ using $3 \mathrm{D} \mathrm{EM}$ simulator to locate the sixth antinode as demonstrated by Fig. 6 where it is evident that each element is appropriately excited. Distance $\mathrm{X}$ was set at $10 \mathrm{~mm}$ to prevent spurious incoming antinodes.

Figure 7 shows the standard long wire antenna, differently loaded wire antennas which include more particularly, the planar H-shaped element loaded transmission-line design, optimized for maximal radiation efficiency and directivity. These antennas were fabricated in our lab on Duroid laminate board in order to compare them with the proposed array in a bid to underpin QLER specific advantages. Good examples of these antennas were reported by Simovski and $\mathrm{He}$, using photonic bandgap (PBG) to improve the radiation characteristics while maintaining a reasonably small antenna size [14]. The difference therefore between these antenna and the ones reported by 


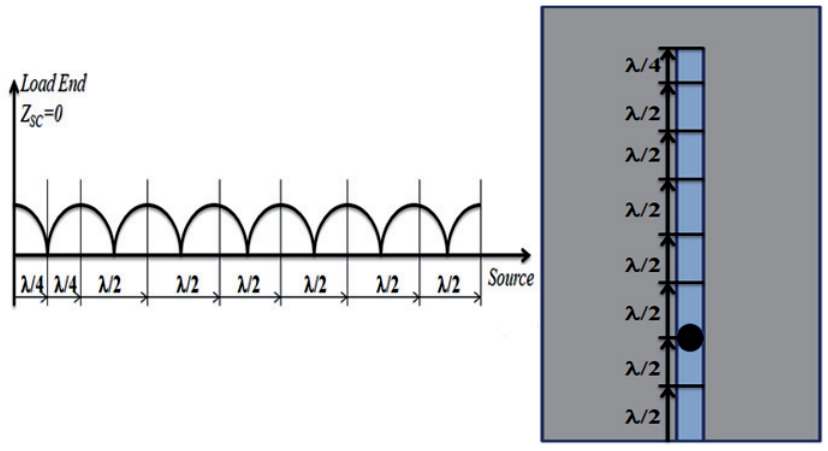

Fig. 5. Voltage allocation over a microstrip line with a shorted load end.

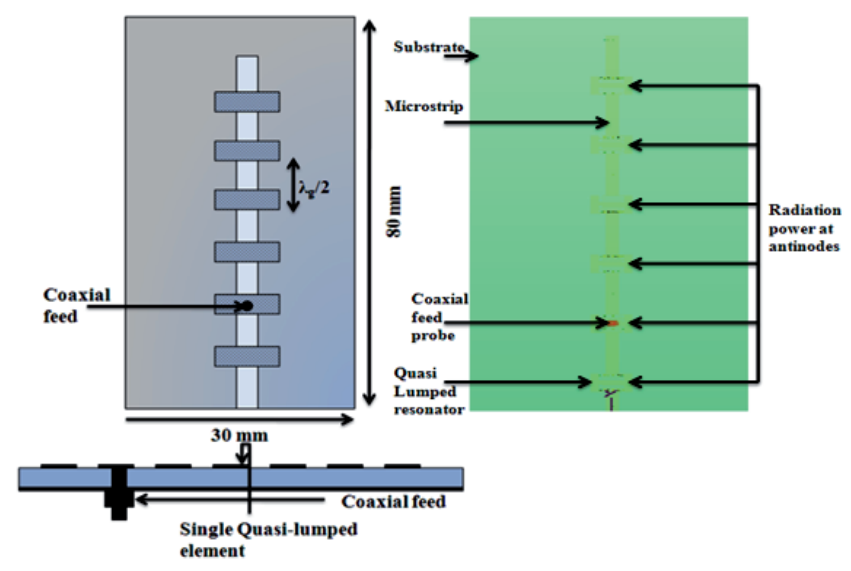

Fig. 6. Geometries of the proposed antenna array.

Simovski and $\mathrm{He}$ is that the proposed design is photo etched on a laminate Duroid RO4003C microwave substrate board as against PBG used in their work. These antennas were similarly fed with microstrip feed of width $1.898 \mathrm{~mm}$ and were excited with a coaxial probe. The essence of these designs as earlier mentioned is to provide common platforms to compare in detail the specific advantages of the proposed antenna as compared to these wire antennas.

\section{Results and Discussions}

An HP 8720 Network Analyzer was used to measure the reflection coefficient, impedance bandwidth, resonant frequencies, and input impedance as reported in this paper. The two-dimensional planes corresponding to E-plane and $\mathrm{H}$-plane radiation patterns were measured with a combination of HP $83620 \mathrm{~B}(10 \mathrm{MHz}-20 \mathrm{GHz})$ signal generator, a transmitting dipole antenna, a rotating machine and Agilent $8565 \mathrm{E}(9 \mathrm{kHz}-50 \mathrm{GHz})$ spectrum analyzer.

The antenna under test (AUT) was attached to the rotating machine while the standard transmitting horn antenna was attached to a fixed stand. The proposed antenna (AUT) acts as a receiving antenna. Both the receiving and transmitting antenna were strategically positioned to ensure that there is alignment between them. It is also imperative that the two antennas (transmitting and
AUT) maintain a distance sufficiently large enough from each other such that the distance falls within AUT far-field.

The minimum permissible distance depends on the dimensions of the antenna in relation to the wavelength. Thereafter, the transmit signal power level was set at $5 \mathrm{dBm}$ right on the signal generator at the set measurement frequencies. The radiation pattern will normally be observed on the screen of the spectrum analyzer and the power level at the transmit frequencies were measured. Usually, one part of the measurement is done on the polarization plane which is E-plane whereas the other will be on a plane perpendicular to the polarization plane. For an Eplane cut, the resonator was aligned so that it was horizontally polarized while the holder was rotated from $0^{\circ} \sim 360^{\circ}$ such that the measurements were taken at 10 degree intervals. For H-plane cut, the resonator was moved in such a way that it was vertically polarized while the holder was rotated. Besides, H-plane cut can also be carried out by orienting the position of the transmitting antenna such that it becomes vertically polarized. Thereafter, the cable power loss was subtracted from the received power to get the actual received power. These values are normalized with a maximum value of the received power to get the normalized received power.

Figure 8(a) shows the simulated and measured reflection coefficient of the single QLER antenna and the array configuration. The level of maximum coupling is better than $-10 \mathrm{~dB}$ over a bandwidth of $5.76-5.79 \mathrm{GHz}$ for simulated results and 5.71-5.92 GHz for the measurement (over which gain and maximum sidelobe levels varied by no more than $1 \mathrm{~dB}$ ) with a measured input impedance of (50.701 $-\mathrm{j} 1.09) \Omega$ and VSWR of 1.03:1. The reflection coefficient results of the proposed antenna array showed that the frequency bandwidth is $5.77-5.98 \mathrm{GHz}$ with input impedance of $(49.31+\mathrm{j} 1.57) \Omega$ and VSWR of $1.44: 1$. In Fig. 9, the radiation patterns of a single QLER antenna and their array configurations were depicted.

For the single element, the main lobe magnitude is $7 \mathrm{~dB}$ with main lobe direction oriented at 6 degrees, angular width $(3 \mathrm{~dB})$ of 30.4 degrees and a gain of $9.4 \mathrm{dBi}$. In E- and H-planes of the proposed antenna, the simulated radiation pattern of the main lobe magnitude of E-plane is $13.8 \mathrm{~dB}$ oriented in zero degree direction with a sidelobe level of $-11.91 \mathrm{~dB}$.

The angular width $(3 \mathrm{~dB})$ is 16.3 degrees (which is 46.38\% narrower than the single QLER antenna beamwidth) with an experimental gain of $12.17 \mathrm{dBi}$. The $\mathrm{H}-$ plane magnitude is the same, but with a relatively wider beamwidth. There is a significant agreement between the simulated and theoretical radiation pattern on both planes, with minor dissimilarities in terms of the sidelobe pattern though of the same average magnitude. However, there is a noticeable difference between the experimental and theoretical/simulated mainlobe magnitude (in $\mathrm{dB}$ ) in both planes, with the experimental mainlobe magnitude lower than the simulated by $0.05 \%$. 


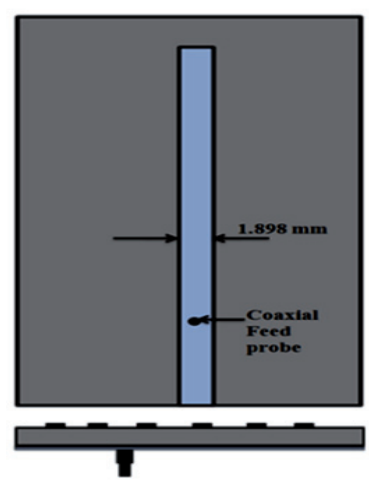

(a)

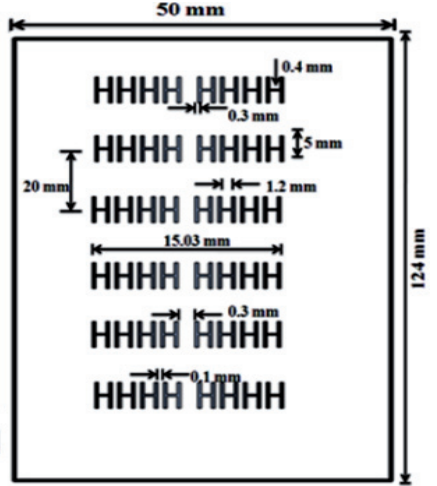

(b)

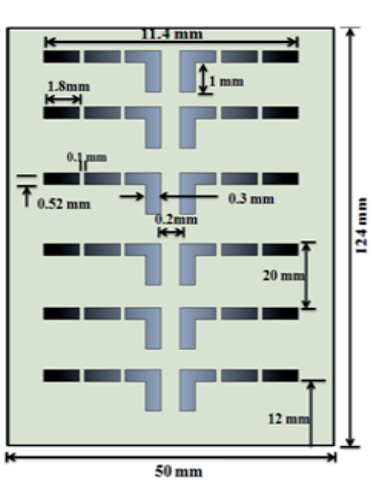

(c)

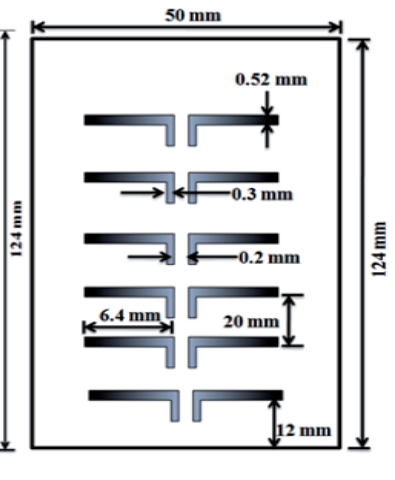

(d)

Fig. 7. Geometries of different antenna configurations. (a) Feeding technique, (b) Planar H-shaped, (c) Capacitively loaded, (d) Conventional wire antenna.

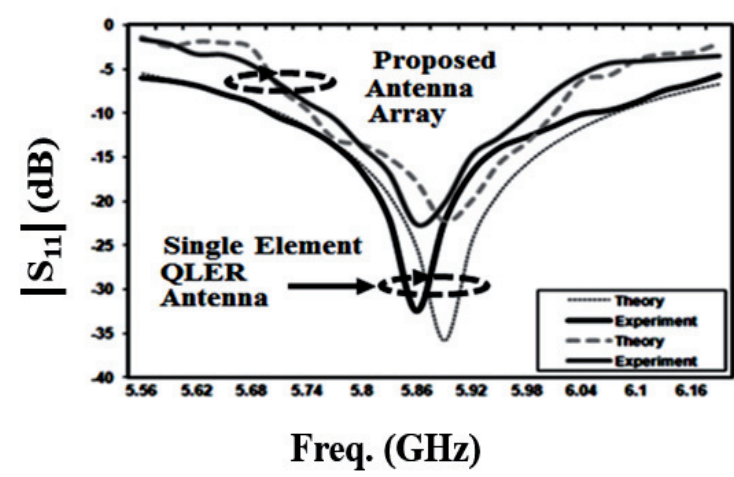

(a)

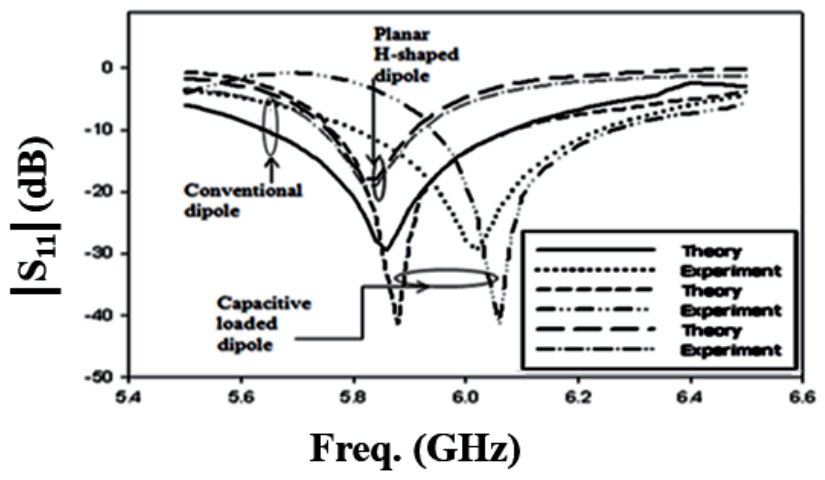

(b)

Fig. 8. Reflection coefficients of the antennas. (a) Proposed antenna, (b) Fabricated antenna for comparison.

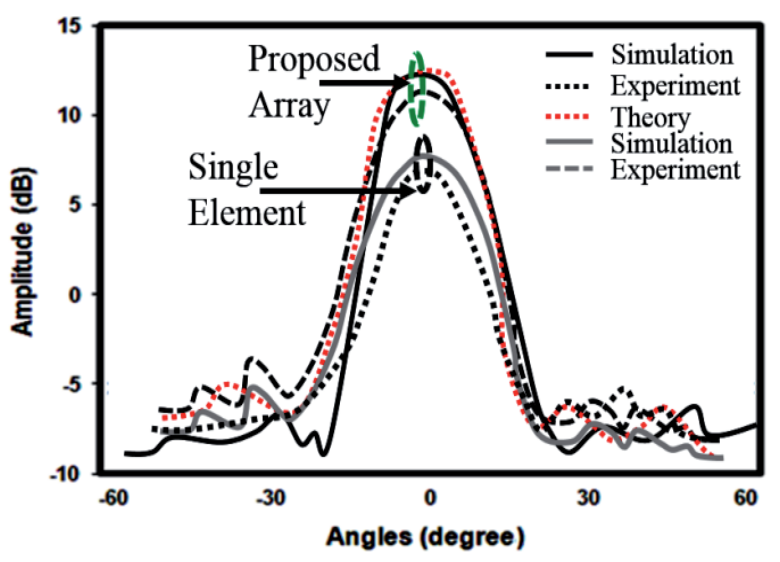

(a)

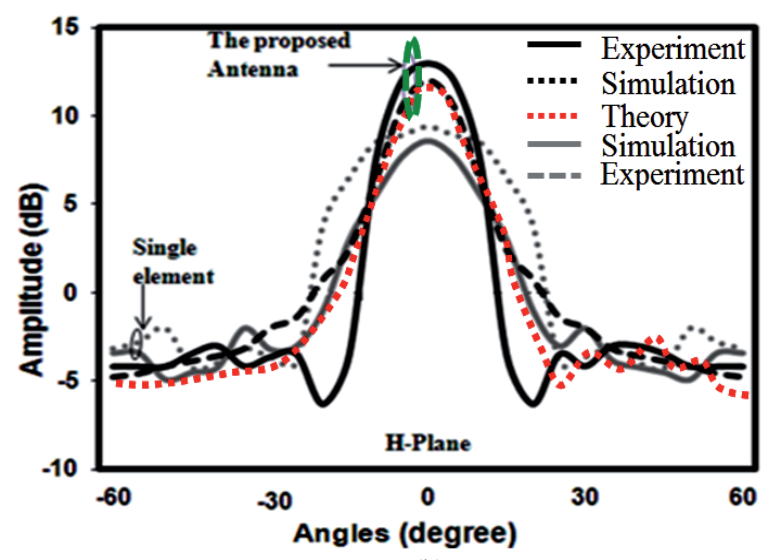

(b)

Fig. 9. Radiation pattern of the proposed antenna configuration. (a) E-plane, (b) H-plane.

Figure 8(b) shows the reflection coefficient pattern for the wire antennas. Their maximum level of coupling was better than $-10 \mathrm{~dB}$. More particularly, the capacitively loaded wire antenna presents the best coupling coefficient and directly followed by the conventional dipole antenna.

Planar $\mathrm{H}$-shaped wire antenna had the worst reflection coefficient although much better than $-10 \mathrm{~dB}$. Tab. 2 and 3 respectively show the experimental and the published work performance profile comparison of different long wire antennas. This further supports quantitative, a brilliant performance of the proposed antenna compared to the long wire antenna irrespective of their performance. The QLER antenna proves its superiority in terms of gain and antenna size reduction, particularly with respect to its dimensions. Though, the planar $\mathrm{H}$-shaped wire antenna presents a much better gain among the wire antennas as shown in Tab. 2, and directly followed by capacitively loaded wire antenna; the conventional dipole antenna has the least gain although much better than $7.5 \mathrm{dBi}$. 


\begin{tabular}{|c|c|c|c|c|}
\hline $\begin{array}{c}\text { Antenna } \\
\text { Type }\end{array}$ & $\begin{array}{c}\text { Bandwidth } \\
\text { (MHz) }\end{array}$ & $\begin{array}{c}\text { Gain } \\
(\mathrm{dB})\end{array}$ & $\begin{array}{c}\text { E-Plane } \\
\text { Beamwidth } \\
\text { (degree) }\end{array}$ & $\begin{array}{c}\text { Size } \\
\text { (sq. mm) }\end{array}$ \\
\hline $\begin{array}{c}\text { Proposed } \\
\text { QLER }\end{array}$ & 242 & 12.17 & 16.3 & $80 \times 30$ \\
\hline $\begin{array}{c}\text { Conventional } \\
\text { Printed } \\
\text { Dipole }\end{array}$ & 320 & 7.53 & 30.2 & $124 \times 50$ \\
\hline $\begin{array}{c}\text { Capacitively } \\
\text { Loaded } \\
\text { Dipole }\end{array}$ & 220 & 7.76 & 21.9 & $124 \times 50$ \\
\hline $\begin{array}{c}\text { Planar } \\
\text { H-shaped } \\
\text { Transmission } \\
\text { Line }\end{array}$ & 140 & 10.23 & 17.3 & $124 \times 50$ \\
\hline
\end{tabular}

Tab. 2. The experimental performance profile comparison with the proposed antenna.

It is noteworthy that both the conventional dipole antenna array and the other performance enhancement planar long wire antenna arrays look promising in terms of gain, bandwidth, and beam width. Even at a worst case scenario, their least gain and impedance bandwidth were in the neighborhood of $7.64 \mathrm{dBi}$, and $140 \mathrm{MHz}$ respectively, with the E-plane beamwidth of 17.3 degree. However, as awesome as these results, they are much inferior to what is obtained by the proposed antenna.

Table 3 gives a quantitative yet explicit description of the robustness of the proposed antenna over the many performance enhancement antennas reported in the literatures (some of which are listed in Tab. 3) irrespective of their performance enhancement configuration. Though in Tab. 3, the slot-coupled microstrip array antenna presents a much better directive characteristics of about $14.5 \mathrm{dBi}$ (for an array of $2 \times 8$ element with an element size of $7.61 \times 7.61$ sq. $\mathrm{mm}$ ), followed by the patch array with a gain of $19 \mathrm{dBi}$ but both with an expansive antenna estate occupation of about $221 \times 50$ sq. $\mathrm{mm}$ at a resonant frequency of $10.5 \mathrm{GHz}$, and $1500 \mathrm{sq}$. mm (even with a substrate thickness of $1.59 \mathrm{~mm}$ ) at a frequency of $5.3 \mathrm{GHz}$ respectively as shown in the table. This large aperture size along with commensurate antenna estate area makes the duo very unattractive where size is a premium.

\begin{tabular}{|c|c|c|c|c|c|c|c|c|c|c|c|c|}
\hline $\begin{array}{l}\text { Antenna } \\
\text { Type }\end{array}$ & Author & Feed Type & $\begin{array}{c}\text { Resonant } \\
\text { Freq. } \\
(\mathrm{GHz})\end{array}$ & $\begin{array}{c}\text { Bandwidth } \\
\text { (MHz) }\end{array}$ & $\begin{array}{l}\left|\mathrm{S}_{11}\right| \\
(\mathrm{dB})\end{array}$ & VSWR & $\begin{array}{l}\text { Gain } \\
(\mathrm{dBi})\end{array}$ & $\begin{array}{c}\text { Substrate } \\
\text { Thickness } \\
(\mathrm{mm})\end{array}$ & $\begin{array}{l}\text { Substrate } \\
\text { Permit. } \varepsilon_{\mathrm{r}}\end{array}$ & $\begin{array}{c}\text { E-Plane } \\
\text { Sidelobe } \\
(\mathrm{dB})\end{array}$ & $\begin{array}{c}E \text {-Plane } \\
\text { Beamwidth } \\
\text { (degree) }\end{array}$ & $\begin{array}{c}\text { Size } \\
\text { (sq. mm) }\end{array}$ \\
\hline $\begin{array}{l}\text { Proposed } \\
\text { QLER }\end{array}$ & QLER & $\begin{array}{c}\text { Coaxial } \\
\text { Feed }\end{array}$ & 5.79 & 242 & -31.81 & $1.053: 1$ & 12.17 & 0.813 & 3.38 & -12.7 & 15.8 & $80 \times 30$ \\
\hline $\begin{array}{l}\text { Patch } \\
\text { Array }\end{array}$ & [15] & $\begin{array}{l}\text { Teardrop } \\
\text { Probe }\end{array}$ & 2.115 & Not Stated & $\begin{array}{c}\text { Not } \\
\text { Stated }\end{array}$ & $1.05: 1$ & 19 & 3.2 & 2.17 & -20 & 240 & $98 \times 98$ \\
\hline $\begin{array}{c}\text { Wideband } \\
\text { Printed } \\
\text { Dipole } \\
\end{array}$ & [16] & $\begin{array}{l}\text { Twin-Feed } \\
\text { Line }\end{array}$ & 0.78 & $47 \%$ & $\begin{array}{c}\text { Not } \\
\text { Stated }\end{array}$ & $1.70: 1$ & 11.9 & 3.20 & 2.17 & -16 & Not Stated & Not Stated \\
\hline $\begin{array}{c}\text { Slot } \\
\text { Coupled } \\
\text { Microstrip } \\
\text { Array } \\
\end{array}$ & [17] & $\begin{array}{l}\text { Series- } \\
\text { Feed } \\
\text { Network }\end{array}$ & 10.5 & 300 & -28 & 1.083:1 & 14.5 & 0.508 & 3.38 & -14.9 & 60 & $221 \times 50$ \\
\hline $\begin{array}{l}\text { Capacitive } \\
\text { Loaded } \\
\text { Long Wire }\end{array}$ & [14] & $\begin{array}{l}\text { Coaxial } \\
\text { Feed }\end{array}$ & 3.2 & Not Stated & $\begin{array}{l}\text { Not } \\
\text { Stated }\end{array}$ & $\begin{array}{l}\text { Not } \\
\text { Stated }\end{array}$ & 0.001 & BPG & BPG & $\begin{array}{l}0.00025 \\
\text { H-Plane }\end{array}$ & $\begin{array}{c}60 \\
H \text {-Plane }\end{array}$ & $40.4 \times 1$ \\
\hline $\begin{array}{c}\text { Planar } \\
\text { H-shaped } \\
\text { Line }\end{array}$ & [14] & $\begin{array}{c}\text { Coaxial } \\
\text { Feed }\end{array}$ & 3.2 & Not Stated & $\begin{array}{c}\text { Not } \\
\text { Stated }\end{array}$ & $\begin{array}{c}\text { Not } \\
\text { Stated }\end{array}$ & 0.0025 & BPG & BPG & $\begin{array}{c}0 \\
\text { H-Plane }\end{array}$ & $\begin{array}{c}60 \\
H \text {-Plane }\end{array}$ & $40.4 \times 5$ \\
\hline
\end{tabular}

Tab. 3. The published work performance profile comparison with the proposed antenna.

The wideband printed dipole antenna, capacitively coupled long wire transmission line, as well as the planar $\mathrm{H}$-shaped wire antenna also present relatively inferior results of $11.9,0.001,0.0025 \mathrm{dBi}$ gain, though with a very compact (and different objectives) area occupations of $40.4 \times 1$ sq. $\mathrm{mm}$, and $40.4 \times 5$ sq. mm respectively. Similarly, the aperture size of capacitively coupled long wire transmission line, and the planar H-shaped wire antenna are reasonable, but both are unattractive particularly (other than their design objectives) in terms of directivity due to poor gain.

\section{Conclusions}

A six-element QLER antenna array has been proposed in this paper. The necessary spatial orientation of its radiation pattern equations were derived, plotted using
Matlab code, and also presented. The inter-element spacing of $\lambda / 2$ was used based on voltage allocation on an openended microstrip line, using the necessary dissipation equations of microstrip transmission line.

The theoretical, numerical (through computer simulation), and experimental results were investigated, and compared with existing works presented in the literatures. It is evident that the proposed antenna has a gain of $12.17 \mathrm{dBi}$, a beamwidth of 16.3 degrees, and much compact size advantage. In addition, the design is feasible, realizable and cost effective.

Further comparison with other different printed wire antenna configurations confirmed that the proposed antenna has relative advantages in terms of overall gain, antenna size reduction with reasonable bandwidth. More so, the proposed antenna offers a higher degree of design freedom and flexibility. 


\section{References}

[1] BAHL, I. Lumped Element for RF and Microwave Circuits. Artech House; 2003. ISBN 1-58053-309-4

[2] HARRINGTON, R. F. Time-harmonic Electromagnetic Fields. New York: McGraw Hill; 1961. ISBN: 978-0-471-20806-8

[3] AIN, M. F., HASSAN, S. I. Design of $2 \mathrm{GHz}$ quasi-lumped element oscillator. In Proceedings of $R F$ and Microwave Conference. 2004, p. 13-16, DOI: 10.1109/RFM.2004.1411061

[4] AIN, M. F., OLOKEDE, S. S., QASAYMEH, Y. M., MARZUKI, A., MOHAMMED, J. J., SREEKANTAN, S., HUTAGALUNG, S. D., AHMAD, Z. A., ABDULlA, M. Z., A novel $5.8 \mathrm{GHz}$ quasilumped element resonator antenna. AEU - International Journal of Electronics and Communications, 2013, vol. 67, no. 7, p. 557-563. DOI:10.1016/J.AEUE.2012.12.008

[5] SCHNEIDER, M. V. Microstrip lines for microwave integrated circuits. The Bell System Technical Journal, 1969, vol. 48, no. 5, p. 1421-1444. DOI: 10.1002/j.1538-7305.1969.tb04274.x

[6] GANESAN, L., SREEJA-MOLE, S. S., Transmission Lines and Wave Guides. New Delhi: Tata McGraw Hill, 2010.

[7] DAWOUD, M. M., ANJAD, M. K. Analytical solution for mutual coupling in microstrip patch antenna arrays, The Arabian Journal for Science and Technology, Jan. 2005, vol. 31, no. 1B.

[8] HUANG, F., AVEnHAUS, B., LANCASTER, M. J. Lumpedelement switchable superconducting filters. IEE Proceedings on Microwave, Antennas and Propagation, June 1999, vol. 146, no. 3, p. 299-233.DOI:10.1049/ip-map:19990357

[9] MEIXNER, J. The behaviour of electromagnetic fields at edges. IEEE Transactions on Antennas and Propagation, July 1972, vol. 20, no. 4, p. 442-446. DOI: 10.1109/TAP.1972.1140243

[10] MITTRA, R., LEE, S. W. Analytical Techniques in the Theory of Guided Waves. McMillan. 1971. ASIN: B0006C0E1M

[11] SHIH, Y. C., ITOH, T. Analysis of conductor-backed coplanar waveguide. Electronics Letters, June 1982, vol. 18, no. 12, p. 538 to 440 . DOI: $10.1049 / \mathrm{el}: 19820365$

[12] ITOH, T., MENZEL, W. A full-wave analysis method for open microstrip structures. IEEE Transactions on Antennas and Propagation, Jan. 1981, vol. AP-29, no. 1, p. 63-68. DOI: 10.1109/TAP.1981.1142520

[13] BELANIS, C. A. Antenna Theory, Analysis and Design. 2nd ed. USA: John Wiley \& Sons, 1997. ISBN: 978-0-471-66782-7
[14] SIMOVSKI, C. R., HE, S. Antennas based on modified metallic photonic bandgap structures consisting of capacitively loaded wires. Microwave and Optical Technology Letters, Nov. 2001, vol. 31, no. 3, p. 214-221. DOI: $10.1002 /$ mop.1401

[15] HUANG, J. Microstrip antenna developments at JPL. IEEE Antennas and Propagation Magazine, June 1991, vol. 33, no. 3, p. 33-41. DOI: $10.1109 / 74.88219$

[16] EVTIOUSHKINE, G. A., KIM, J. W., HAN, K. S. Very wideband printed dipole antenna array. Electronics Letters, Nov. 1998, vol. 34, no. 24, p. 2292-2293. DOI: 10.1049/el:19981615

[17] SLOMIAN, I., WINCZA, K., GRUSZCZYNSKI, S. Series-fed microstrip antenna array with inclined-slot couplers as three-way power dividers. IEEE Antennas and Wireless Propagation Letters, 2013, vol. 12, no., p. 62-64. DOI: 10.1109/LAWP.2013.2238212

\section{About the Author ...}

Seyi Stephen OLOKEDE received his B. Eng., and M.Sc. from the Dept. of Electrical Engineering, University of Ilorin, Ilorin, Kwara State, Nigeria in 1994, and 2001 respectively, and Ph.D. degree in Wireless and Mobile System from the School of Electrical and Electronic Engineering, University of Science, Penang, Malaysia. Between 1999 and 2003, he was with the University of Ilorin and subsequently joined the College of Engineering, Olabisi Onabanjo University in 2004. Dr. Seyi Olokede won the institute of post-graduate school graduate assistant award of the Universiti of Science, Penang, Malaysia, between 2011-2012 and 2012-2013, and formerly, a Pascal Doctoral Fellow of the university. His research interests include applied electromagnetic, bio-electromagnetic, microwave circuits design and miniaturizations, EMC, microwave sensors, and tomography. He is a member of the Institute of Electrical and Electronic Engineering (IEEE), and currently serves on review board of few top ranking journals including IEEE Transaction on Antenna and Propagation Magazine. 